INNOVACIÓN

\title{
Algunas herramientas para desmontar prejuicios y estereotipos en la enseñanza jurídica
}

\author{
Algumas ferramentas para desconstruir preconceitos \\ e estereótipos na educação jurídica
}

Tools to dismantle prejudices and stereotypes in legal education

\author{
Nancy Cardinaux \\ Universidad de Buenos Aires, Argentina
}

RESUMEN Desde siempre, la enseñanza jurídica se ha enfrentado a prejuicios y estereotipos que a veces combate o legitima. En la actualidad, los prejuicios y, sobre todo, los estereotipos, reforzados por algoritmos que permiten construir datos acerca de personas y colectivos, son difíciles de desmontar. Este artículo esboza herramientas que pueden resultar útiles para tratar de deconstruir los estereotipos que operan tanto en la enseñanza jurídica como en el campo jurídico en general. El trabajo sobre las emociones, la descripción densa y la conciencia de incompletitud de la cultura propia, son descritos e interrogados de cara a su capacidad de desmontar los lugares comunes sobre los que muchas veces operamos.

PALABRAS CLAVE Prejuicios, estereotipos, educación jurídica.

RESUMO A educação jurídica sempre enfrentou preconceitos e estereótipos contra os quais ora luta e ora legitima. Atualmente, preconceitos e principalmente estereótipos, reforçados por algoritmos que nos permitem construir dados sobre pessoas e grupos, são difíceis de desmontar. Este trabalho delineia ferramentas que podem ser úteis para tentar desconstruir aqueles estereótipos que operam tanto na educação jurídica quanto no campo jurídico em geral. O trabalho sobre as emoções, a densa descrição e a consciência da incompletude da própria cultura são descritos e questionados em vista de sua capacidade de desmantelar os lugares comuns em que muitas vezes operamos.

PALAVRAS-CHAVE Preconceitos, estereótipos, educação jurídica. 


\begin{abstract}
Legal education has always confronted prejudices and stereotypes, against which it sometimes fights and sometimes legitimizes. In the present, prejudices and especially stereotypes, reinforced by algorithms that allow building data about people and groups, are difficult to disassemble. This work outlines tools that can be useful to try to deconstruct those stereotypes that operate, both in the legal education as in the legal field in general. The work on emotions, dense description and incompleteness awareness of the own culture are described and questioned regarding their ability to dismantle the common places on which we often operate.
\end{abstract}

KEYWORDS Prejudices, stereoypes, legal education.

El dolor es la verdad, todo lo demás está sujeto a duda. -J. M. Coetzee

\title{
Introducción: De expectativas a estereotipos
}

El mundo social se organiza en torno a expectativas que nos dejan prever las conductas de quienes nos rodean en base al conocimiento de los status que detentan y los roles que ejercen. Así, por ejemplo, al status de maestro se le asigna un set de roles que se espera que sean cumplidos y, en general, nuestras expectativas se verifican a la par que las experiencias mientras esos status producen resignificaciones de los roles que esperamos de ellos.

Las expectativas son, en sí mismas, un problema en cuanto se espera algo de nosotros en relación con cada uno de nuestros status, ya sean adscriptos (como el género, la edad o la clase social) o adquiridos (aquellos que requirieron alguna acción y supuesta elección de nuestra parte, como el ejemplo del magisterio del que partimos). Por supuesto, las elecciones que fundan status adquiridos deben lidiar con todos los obstáculos que la autonomía tiene en general, y que se intensifican en sociedades profundamente desiguales. Así, por ejemplo, ciertas profesiones están claramente asociadas a determinados status adscriptos, como el género, el color de piel o la clase social, entre otros. El status de juez puede estar vedado para quienes tienen determinados status formalmente o en forma velada, es decir, a través de pautas sociales que dificultan y hasta impiden su acceso a quienes no estén socialmente admitidos. La escasez de chances de obtener una posición en general inhibe los intentos de personas que, bajo otras condiciones, desearían hacerlo. Como sostiene Elster, muchas veces convertimos las oportunidades en deseos, aunque la influencia sobre nuestra conducta de lo que deseamos y nuestras oportunidades es altamente compleja. ${ }^{1}$

Ahora, estas expectativas pueden ser transformadas en estereotipos. Veamos un caso literario. Nos referiremos al narrador de una novela en la que se relata un proceso de seducción y violación de una niña obrera, lo que nos recuerda, por supuesto, 
a aquel niño proletario de Lamborghini. Así, se describen del siguiente modo los atributos que se asignan a la niña:

La ausencia especial de Delia durante esa caminata tenía para mí semejanza con sus letargos fabriles; eran las formas diversas de una misma disposición sentimental, nada más que adaptada a situaciones diferentes. Y para evitar el trabajo de encontrar palabras quizá más adecuadas - pero menos gráficas- llamaré a esos letargos o ausencias de Delia su «disposición proletaria». La verdad es que no sé si los obreros tienen una idiosincrasia particular; después de conocer a Delia y a unos pocos de sus compañeros tiendo a creer que sí. En cualquier caso uso la fórmula como una simple asociación: la abstracción en las situaciones fundamentales, como frente a la máquina, se repetía en el caso de Delia en varias otras circunstancias. Un tipo de ausencia quizá relacionada con las operaciones cuantitativas que suelen realizar los obreros (Chejfec, 2000: 74-75).

Esos silencios, tal vez, se deban al miedo, a la diferencia de edad, de clase o a la relación de dominación misma. Sin embargo, desde un interés particular se va despojando a la niña de su subjetividad en base a supuestos atributos que se le asignan en tanto obrera.

Es vasta la literatura que da cuenta de estas secuencias de transformación de la alteridad en nuda vida y, desde ahí, ya no hay persona ni derechos que valgan. En la novela de Chejfec, sobre el final, el narrador vuelve a justificar la acción de Delia en la misma supuesta «disposición proletaria»:

Ya sea una fuerza que la psicología de los obreros transmite a las máquinas, o sea una fuerza que actúa al revés, desde la máquina hacia la mente del obrero, lo cierto es que la fortaleza de Delia para esperar y esperar, más allá del sitio y sin importar el clima, si bien podía deberse a su corazón sorprendido, para decirlo de algún modo, se nutría de esa fuerza inconmovible que provenía de su condición proletaria. Como tenía la virtud de aparecer en medio de mi camino, y como obviamente yo debía verla antes de apartar la mirada, pude ver también cómo su barriga crecía uniforme. Era tan joven que el embarazo paradójicamente subrayaba su inocencia, la hacía parecerse a una niña que hubiese descubierto un mecanismo secreto del juego, o una presa que no había conseguido la piedad del cazador (Chejfec, 2000: 179-180).

Aquí es subrayable cómo lo que el narrador llama apariencia es para quienes leemos lo que Delia es: una niña embarazada y desesperada. El narrador, en cambio, ve paradojas donde no las hay y desdeña lo que no puede dejar de ver en favor de una concepción acerca del status de obrera, que, por supuesto, responde a su interés.

Si bien estas situaciones pueden ser descritas con el concepto de prejuicio, es preferible el de estereotipo, porque se pueden tener prejuicios con respecto a una categoría de personas, pero también con respecto a alguna actividad o situación concreta. 
El término «estereotipo», en cambio, especifica al de prejuicio, en cuanto lo relaciona con una categoría de personas, un colectivo, un agrupamiento. $\mathrm{Y}$ es eso lo que queremos denotar aquí, aunque, como el prejuicio, el estereotipo reconoce niveles que seguramente van desde los que nos impiden tener otra relación que la de subordinación con las personas estereotipadas hasta el deseo o práctica de exterminio de su categoría.

Es importante mantener una vigilancia epistemológica sostenida con respecto a aquellas expectativas que ordenan la vida social, porque muchas de ellas fundan o cristalizan desigualdades con los estereotipos como mediadores o justificadores. Las expectativas son propias de la vida social, pero debemos estar muy alertas a los atributos que asignamos a quienes tienen un status adscripto o adquirido (en general subordinado): niños, adultos mayores, discapacitados, migrantes, personas pertenecientes a los estratos sociales inferiores, etcétera. Y, por supuesto, a la intersección entre categorías, que puede hacer, por ejemplo, que el prejuicio no se active con respecto a un migrante, pero sí ante una mujer migrante.

En esos casos, es posible que nos encontremos frente a estereotipos que resultan inamovibles porque se trata de prejuicios reforzados, en el sentido de que no pueden ser permeados por la experiencia o la teoría. Todo el conocimiento que refute los atributos del estereotipo será desdeñado, porque se lo considerará aparente, excepcional o se recurrirá a alguna de las muchas estrategias de negación que incorporamos en nuestro proceso de socialización. ${ }^{2}$

Para terminar esta introducción, recurriremos nuevamente a la literatura, en la voz de un personaje que es un exitoso artista plástico que narra su relación con las mujeres:

No me gusta tener novias. Salí con algunas chicas pero nunca funcionó. Tarde o temprano empiezan a reclamarme más tiempo o pedirme que diga cosas que en realidad no siento. Una vez probé decir lo que sentía y fue peor. Otra vez, una con la que había salido como seis veces y ya decía que era mi novia, se volvió completamente loca sin que yo dijera nada. Decidió que yo no la amaba, que nunca iba a amarla, me obligó a agarrarla de los pelos y empezó a darse sola la cabeza contra la pared, mientras gritaba «quiero que me mates, quiero que me mates». Pienso que relaciones así no son sanas. Mi representante, que es el tipo que se encarga de poner mis cuadros en las galerías

2. Dice Cohen (2005: 25) sobre la negación: «La psicología del «evitar ver» o «mirar para otro lado» es un asunto delicado. Estas frases implican que tenemos acceso a la realidad, pero elegimos ignorarla porque es conveniente hacerlo. Esto podría ser un simple fraude: la información está disponible y es registrada, pero lleva a una conclusión que es evadida de forma consciente. «Saber», sin embargo, puede ser mucho más ambiguo. Somos vagamente conscientes de elegir no observar lo que sucede, pero no completamente conscientes de qué exactamente estamos evadiendo. Sabemos, pero al mismo tiempo no sabemos». 
y decidir qué precio tiene cada cosa que hago, dice que el tema de las mujeres no me conviene. Dice que la energía masculina es superior, porque no se dispersa y es monotemática. Monotemática es que solo piensa en una cosa, aunque nunca dice en cuál. Dice que las mujeres son buenas al principio, cuando están bien buenas, y buenas al final, porque vio morir a su padre en brazos de su madre y esa es una buena forma de morir. Pero todo lo que está en el medio es un infierno (Schweblin, 2017: 114-115).

El protagonista y narrador del cuento está atento a su propio infierno, y los otros no son vistos más que como personajes (no personas) que no le dejan otra salida que la violencia. Sobre el final, cuando ha matado otra vez, en virtud de una «brecha cultural» que no le permitía ser amigo de su dentista coreano, reflexiona:

La gente dice que soy un racista, un hombre descomunalmente malo, pero mis cuadros se venden por millones y yo empiezo a pensar en eso que siempre decía mi mamá, eso de que el mundo lo que tiene es una gran crisis de amor, y de que, al fin y al cabo, no son buenos tiempos para la gente sensible (Shweblin, 2017: 123).

En ese cuento, Schweblin juega con los tópicos básicos de la discriminación, pero asumidos por el discurso del violento. Su sensibilidad no es comprendida por las mujeres ni tampoco por los coreanos, japoneses o chinos (que no distingue). Las «brechas culturales» impiden su relación de amistad con un extranjero. Su manera de resolver estos conflictos siempre es esa violencia extrema que ejerció por primera vez con sus compañeros de colegio aunque, claro, si hay serpiente hubo huevo, y en el relato aparece el protagonista como víctima de burlas por parte de otros niños. Por último, el éxito que tiene como reconocido artista, cuyos cuadros se venden por altos precios, parece marcar que todo no está tan mal. Es, en definitiva, su extrema sensibilidad la que lo conduce a la extrema violencia. Si sus pinturas de cabezas aplastadas son tan exitosas, algo parece decirnos Schweblin acerca de lo que la sociedad busca (comprando las pinturas o prendada morbosamente de los detalles de los crímenes), pero a la vez repele.

\section{Los estereotipos en el campo jurídico}

En los últimos años, el campo jurídico se ha hecho cargo crecientemente de las influencias que en todos sus niveles tienen los prejuicios en general y los estereotipos en particular. ${ }^{3}$ La expansión del enfoque de género ha contribuido, de manera importante, a visibilizar y desnaturalizar en la arena judicial algunos estereotipos que no resisten su cotejo con datos cuantificables o no cuantificables, que en su mayoría están disponibles hace mucho tiempo. Por supuesto, no se trata de un problema novedoso, y así ha sido estudiado desde diversos puntos de vista. De esta forma, por ejemplo, la selectividad penal da cuenta de los estereotipos que se han aplicado y siguen aplicándose en ámbitos que se presumen neutrales a esos mismos juicios de valor negativos. 
Esas ya longevas líneas de investigación, dan cuenta de las dificultades que los datos y sus interpretaciones tienen para producir cambios en un campo como el jurídico, que ofrece un sinnúmero de resistencias.

Los estereotipos, por supuesto, están fuertemente naturalizados, y hace falta saber cómo desnaturalizarlos y volverlos visibles para todos. Clérico (2017: 209) enfatiza la necesidad de enseñar las técnicas para descubrir estereotipos:

El abordaje de estereotipos como contenido de enseñanza siempre tuvo mayor presencia en sociología jurídica o criminología o derecho penal. Sin embargo, no abunda en derecho constitucional ni en derechos humanos ni en asignaturas que se encargan de formar en metodologías de adjudicación de derechos, sea como fuera su nombre.

Y ese diagnóstico nos interpela a quienes investigamos en el campo sociojurídico.

Las ciencias sociales asociadas al derecho han hecho una labor importante a la hora de desenmascarar estereotipos, pero han sido poco efectivas en la construcción de puentes que permitan que los profesionales del derecho las tomen en cuenta. Desde luego, esa falencia no es exclusiva responsabilidad de la comunidad de las ciencias sociales aplicadas al derecho, sino que es una vacancia, sobre todo institucional. Las facultades de derecho cuentan con canales a través de los cuales la doctrina legal, que en ellas se genera, circula hacia los órganos decisorios en la aplicación de normas ( $y$ en menor medida, en la creación legislativa). A diferencia de otras disciplinas, el derecho ha sabido generar esos puentes, en parte porque muchas veces los mismos profesores de derecho que generan doctrina tienen como principal actividad otra profesión jurídica. Sin embargo, esto es mucho más costoso en el caso de las ciencias sociales aplicadas al estudio del derecho. ${ }^{4}$

Es posible que las técnicas que los juristas buscan ya hayan sido desarrolladas por las ciencias sociales, aunque hay que decir que los estereotipos son difíciles de desenmascarar, justamente, por su astucia para reargumentar y resucitar apenas la evidencia empírica trata de mostrar sus bases prejuiciosas. Tomemos de la literatura una ilustración de esa astucia:

4. Sobre las disciplinas sociales que construyen sus objetos de estudio sobre diversas aristas del derecho, van Hoecke (2014), mostrando que se trata de un problema extendido en diversas comunidades jurídicas, dice: «Todas estas disciplinas ofrecen investigación empírica y construyen teorías en cuestiones jurídicas. No obstante, estas últimas no pretenden reemplazar la doctrina jurídica. Únicamente buscan proveer de información valiosa de la realidad jurídica a los investigadores y operadores jurídicos, así como a quienes elaboran políticas públicas. Desafortunadamente su impacto ha sido muy limitado. De forma que, actualmente, existe una situación esquizofrénica en la que mientras que una disciplina (la doctrina jurídica) básicamente estudia el derecho como un sistema normativo, limitando sus «datos empíricos» a textos jurídicos y sentencias judiciales, otras disciplinas estudian la realidad jurídica, el derecho como es. Los resultados de estas dos disciplinas y vertientes no se entrelazan de forma sistemática, ni se combinan o integran al nivel de la investigación jurídica». 
El muerto había resultado ser un gitano. En la región, había algunos gitanos sedentarios; se habían construido unas casitas en el linde del bosque con la indemnización de daños y perjuicios, que habían recibido por su detención en los campos de concentración. «Por lo visto, por dentro las tienen muy limpias», dijo el dueño. Los policías, que con motivo de la búsqueda del escolar desaparecido habían interrogado a los habitantes de las casitas, se habían quedado sorprendidos al ver el suelo recién fregado y en general el orden existente en el interior. Pero precisamente ese orden, siguió diciendo el dueño, no había hecho más que agravar las sospechas; pues seguramente los gitanos no hubieran fregado el piso de no haber tenido un motivo (Handke, 1994: 76).

Este texto nos recuerda la metáfora de la piedra, que nos dejaba ver la nostalgia de impermeabilidad del pensamiento de la que hablaba Sartre (1985), esa incapacidad para pensar y, en definitiva, ser otra cosa que lo que se pensaba y era.

Los estereotipos no pueden ser desdeñados ni son fáciles de desarmar a partir de información que dé cuenta de su falsedad intrínseca y, sobre todo, de los intereses que encubre. Así, por ejemplo, la interseccionalidad, que es un tópico de esta época, logró ocultar decisiones basadas en estereotipos de «doble entrada». La pregunta que nos anima es qué herramientas pueden ofrecer las ciencias sociales para contribuir a la toma de decisiones en el campo jurídico, que sean capaces de someter a crítica los estereotipos que esa comunidad toma de su contexto y, en particular, de los sectores sociales en que recluta sus agentes.

\section{Las emociones y el conocimiento que refuerzan estereotipos}

Actualmente, contamos con una literatura vasta acerca de las emociones a la hora de tomar decisiones. Lipovetski y Serroy hablan de la "restauración del homo sentiens», 5 y es común que presenciemos, dentro del ámbito jurídico, una búsqueda de cierta sensibilidad más estética que ética que da cuenta de un cierre hacia adentro, es decir, que no religa con los otros, sino con cada cual con sí mismo o con quienes están más cerca. Ese cierre puede consolidar estereotipos en la medida que refuerza una identidad subjetiva y grupal.

Esas emociones suelen cruzarse y anclarse en un conocimiento al que se da por válido, y que cuesta mucho poner en duda, justamente porque su evidencia parece obvia para quienes lo sustentan. La celebración de la empatía, tan importante en los estudios de género, tal vez nos deje en una encrucijada si en lugar de dirigir esa empatía al otro radicalmente diferente o en posición desaventajada, la direccionamos hacia nuestros propios colectivos de pertenencia: 
Era peligroso que una mujer que había sido esclava amara tanto algo, especialmente si ese algo eran sus propios hijos. Él sabía que lo mejor era querer un poquito, quererlo todo, pero solo un poquito, de modo que cuando les rompieran la espalda, o los arrojaran en un saco de desperdicios, te quedara un poco de amor para el siguiente.

No es un dato menor que Morrison ponga esta reflexión en cabeza de un hombre, que marca cómo deben amar las mujeres negras a sus hijos señalando matrices diferentes de una maternidad, que si bien se naturaliza tanto en la cultura dominante como en la subalterna, sin embargo, se bifurca en ese deber ser señalado por un hombre negro. ${ }^{6}$

Así, las emociones no nos salvan de los estereotipos, sino que pueden ser su fuente. Si bien pueden ser una salida de una posición de incomprensión de quienes están en posiciones subalternas, muchas veces permiten ese escape a riesgo de encerrarnos en un cerco, tal vez un poco más ancho, pero siempre reducido a un pequeño número de opciones.

Quizás la diferencia más importante del tiempo que atravesamos sea que gran parte del conocimiento que funda estereotipos ya no está forjado al calor de un sentido común estigmatizante, sino a partir de algoritmos que se presumen neutrales en tanto son construidos en base a datos que tienen varias fuentes: no solo porque son distintos los sujetos que los proporcionan, sino porque algunos de ellos pueden ser considerados datos «duros», mientras que otros son representaciones o percepciones que ya tienen ínsitas prenociones en base a las que se pueden generar o reforzar prejuicios.

En definitiva, los estereotipos pueden basarse tanto en un supuesto conocimiento objetivo como en emociones que nos hacen creer que hacemos empatía en la comprensión. No son fáciles de reconocer y, aún contra toda evidencia empírica, conocimiento teórico y despertar empático, es posible que encuentren armas para defenderse y esas armas se parezcan a las que usamos para atacarlos.

Así, los estereotipos que aplican las burocracias jurídicas se contraponen muchas veces al conocimiento cercano, fidedigno, que permite resolver problemas mucho mejor que los fríos procedimientos del derecho. En una novela de McEwan (2016:44), se contraponen las posibilidades que una jueza de familia y un trabajador social tendrían para tomar una decisión:

6. Sin pretender un cotejo, es interesante leer un estereotipo acerca de los padres de un tiempo y lugar determinado proveniente de una novela de Lorrie Moore (2019: 44): «Y en las sombras largas de su negligencia, nos fabricamos a nosotros mismos, improvisamos nuestras propias reglas en silencio, como lo hacían los niños en Estados Unidos, en los cincuenta y en los sesenta, un tiempo de padres ausentes. Es probablemente por eso que los niños de esa época, cuando crecieron, resultaron semejante shock para sus padres». 
Fiona presidiría el proceso con toda la seriedad y toda la obediencia de un científico nuclear. Dictaminar sobre lo que había empezado con amor y desembocado en odio. Aquel asunto debería habérselo asignado a un asistente social que habría tardado media hora en tomar una decisión sensata.

Aquí, podríamos discutir la noción de «sensatez».7 En su mejor interpretación, estaría ligada a algunas de las dos estrategias de combate de los estereotipos que a continuación sintetizamos.

\section{La descripción densa y el develamiento de la incompletitud cultural}

Las decisiones tomadas en el campo jurídico muchas veces requieren una descripción densa que el derecho no procura y que debe tomar alguna distancia de la empatía, que es posible que tenga muchos beneficios en el descubrimiento del dolor ajeno, pero difícilmente vaya mucho más allá y se convierta en una técnica para desmontar estereotipos. Por supuesto, la empatía permite hacernos carne de la injusticia, del dolor, que lo que consideramos ajeno nos importe, pero de ninguna manera es un vehículo adecuado para producir una descripción densa, que requiere poner en duda todo, empezando por esa empatía que muchas veces tenemos con los de nuestra propia clase o con quienes compartimos algún rasgo en común.

Las teorías de la interpretación tienen diferentes vertientes, que dan lugar a una profunda discusión acerca de los niveles de influencia que las prenociones tienen en nuestros juicios. Basta aquí con mencionar las cumbres alcanzadas por la teoría de Gadamer, que enfatiza el papel de las prenociones en el acto de interpretación ${ }^{8}$ hasta la teoría de Habermas, quien ha tratado de mostrar que las ciencias sociales pueden y deben autonomizarse de esas prenociones, elevando una pretensión emancipatoria. ${ }^{9}$ Sin embargo, aún sosteniendo la posición según la cual somos capaces, merced a ciertos protocolos, de ganar autonomía con respecto a algunas prenociones que actúan como prejuicios, aquí damos por sentado que los mismos operan, la mayoría de las veces, haciendo que naturalicemos y convirtamos en presupuesto justamente lo que deberíamos indagar, poner en tela de juicio. Por supuesto, las ciencias han jugado muchas veces un papel infame, produciendo guiones que no cuestionan, sino que favorecen esos prejuicios.

Describir densamente, interpretar críticamente, es el camino que las ciencias sociales pueden ofrecer para tratar de desmontar los estereotipos a los ojos de quienes quieran ver, y es dado presumir una comunidad jurídica que tenga esa disposición. El concepto de descripción densa de Gilbert Ryle es tomado por Geertz (1973: 24) para fundar la metodología de su antropología cultural:

La etnografía es descripción densa. Lo que en realidad encara el etnógrafo (salvo cuando está entregado la más automática de las rutinas que es la recolección de 
datos) es una multiplicidad de estructuras conceptuales complejas, muchas de las cuales están superpuestas o enlazadas entre sí, estructuras que son al mismo tiempo extrañas, irregulares, no explícitas, y a las cuales el etnógrafo debe ingeniarse de alguna manera, para captarlas primero y para explicarlas después, y esto ocurre hasta en los niveles de trabajo más vulgares y rutinarios de su actividad: entrevistar a informantes, observar ritos, elicitar términos de parentesco, establecer límites de propiedad, hacer censo de casas... escribir su diario. Hacer etnografía es como tratar de leer (en el sentido de «interpretar un texto») un manuscrito extranjero, borroso, plagado de elipsis, de incoherencias, de sospechosas enmiendas y de comentarios tendenciosos y además escrito, no en las grafías convencionales de representación sonora, sino en ejemplos volátiles de conducta modelada.

Desde luego, no resulta sencillo hacer este tipo de descripciones, en las que continuamente estamos atravesados por diferentes estructuras, sentidos, lenguajes, trampas y desvíos. Sin embargo, en el campo jurídico estamos acostumbrados a lidiar con los problemas de interpretación del derecho. Tal vez esas dificultades muchas veces nos llevan a poner un pie firme en las descripciones (a las que muchas veces adjetivamos de «meras» en el sentido de sencillas). Reconocer que las descripciones son tan arduas como las interpretaciones jurídicas acaso sea un buen comienzo, que exige reconocer que estamos mucho menos capacitados para las primeras que para las segundas. Seguramente, quien estudia derecho pasa muchas de sus horas de estudio interpretándolo, pero escasas horas en aprender a describir. Es hora de equilibrar esa balanza y, en lugar de agobiarse con lo que nos falta por saber, tal vez podamos aliviarnos de lo que constituye, según Bachelard, uno de los principales obstáculos epistemológicos: lo que creemos saber. ${ }^{10}$

Jablonka (2017: 11), un historiador que resolvió —-tal vez- agregar algo de ficción a su narrativa del caso de femicidio más notorio de Francia, nos enfrenta a la tarea de describir densamente:

El caso Laëtitia oculta una profundidad humana y cierto estado de la sociedad: familias dislocadas, sufrimientos infantiles mudos, jóvenes que ingresan demasiado pronto en la vida activa, y también el país al comienzo del siglo XXI, la Francia de la pobreza, de las zonas periurbanas, de las desigualdades sociales. A partir de él se descubren los engranajes de la instrucción, las transformaciones de la institución judicial, el rol de los medios, el funcionamiento del Poder Ejecutivo, su lógica acusatoria como su retórica compasiva. En una sociedad en movimiento, el hecho

\footnotetext{
10. En la difícil tarea de enseñar a desmontar estereotipos, la ya clásica advertencia de Bachelard (1999: 21) acerca de otro obstáculo, de corte pedagógico, tal vez siga haciendo falta: «El adolescente llega al curso de Física con conocimientos empíricos ya constituidos; no se trata, pues, de adquirir una cultura experimental, sino de cambiar una cultura experimental, de derribar los obstáculos amontonados por la vida cotidiana».
} 
policial $^{11}$ es un epicentro.

Lo que hace Jablonka en las 400 páginas de su novela es describir densamente, lo cual supone dar cuenta desde los eventos más específicos hasta su relación con otros más generales, pero no por eso menos influyentes. La trama que los une, por supuesto, no es sencilla, y no debe ser banalizada.

Quizás, por eso, la descripción densa pueda complementarse con una visión crítica de la cultura jurídica o, mejor, de las culturas jurídicas como entramados inestables de sentidos que dan cuenta de lo que Geertz (1994: 204) llama «sensibilidades legales», en referencia a que si bien hechos y leyes están presentes en todas las culturas, lo que es propio de cada sensibilidad legal es la relación que se establece entre ellos y que, en nuestro sistema jurídico, llega hasta una absurda polarización en la que pareciera que el derecho puede decir algo y los hechos ser diferentes. Esto es más fácilmente perceptible cuando se observan las culturas en perspectiva histórica o comparada, saliendo de la hegemonía que el concepto de «la» cultura jurídica intenta imponer, como aquel paradigma que imaginaba Habermas a partir del cual se pueden interpretar las decisiones judiciales ejemplares. No es esa ejemplaridad lo que debe buscarse, sino lo que falta, lo que rebasa, lo que esté en los bordes, porque si bien todas las culturas tienen alguna concepción de la dignidad humana, como bien sostiene de Sousa Santos (2000: 69):

Todas las culturas son incompletas y problemáticas en su concepción de la dignidad humana. La incompletitud se deriva del hecho mismo de que existe una pluralidad de culturas. Si cada cultura fuera tan completa como reclama ser, habría una única cultura. La idea de completitud está en el origen de un exceso de significado que parece atormentar a todas las culturas. La incompletitud, entonces, puede apreciarse mejor desde afuera, desde la perspectiva de otra cultura.

Esas incompletas culturas deben ser exploradas en su conformación de sensibilidades legales, de habitus, en sus luchas por el monopolio por decir qué dice el derecho. En sociedades profundamente desiguales en que los estereotipos no logran ocultar, pero sí justifican esa desigualdad, es posible que encontremos muchas homogeneidades, pero debemos estar muy atentos a las divergencias que aparezcan al tratar de definir la relación entre los hechos y el derecho, sus solapamientos, sea lo que entienda cada cultura por esos términos.

En el abordaje del estudio del derecho, las ciencias sociales y las jurídicas pueden decidir separarse para que cada cual juegue su juego o se construyan nuevas reglas

11. Hecho policial es la traducción de la expresión fait divers. La traducción como «hecho diverso», si bien incorrecta, permitiría que nos asomáramos a cuánto nos enseña eso diverso, extraño, fuera de lo común del conjunto, lo cotidiano, lo que damos por sentado. 
de juego. Se separan si las ciencias sociales asumen que cada pueblo tiene su cultura y se abrazan a un relativismo cultural incapaz de fundar un mundo compartido de sentido, mientras el derecho fundamenta de manera trascendente o inmanente los derechos sin pedir auxilio a los estudios culturales o tomando con beneficio de inventario lo que ellos proveen. Un encuentro exitoso es, desde nuestro punto de vista, no una fusión, sino un intercambio de incertidumbres y de herramientas que pueden ayudar a construir provisorias respuestas. Es un escenario complejo, pero no parece presentar más dificultades de las que juristas y científicos sociales están acostumbrados a transitar. Solamente requiere estar abierto a asumir las dificultades ajenas y descansar en lo que ofrece el otro campo.

Descripción densa y asunción de la incompletitud de las culturas a partir de las diversas sensibilidades legales son las herramientas que, entendemos, pueden ofrecer las ciencias sociales al campo jurídico para tratar de deconstruir los estereotipos que fundan, refuerzan o justifican desigualdades. Seguramente, hay otras herramientas más eficaces, pero lo que parece difícil es que el campo jurídico pueda encontrar los remedios y las formas de transformar la sociedad sin recurrir a las ciencias sociales.

Hemos citado a muchos varones; varones que cuentan historias de mujeres y mujeres que toman una posición de enunciación masculina para narrar sobre mujeres. Esto último es lo que hace Clarice Lispector (2015: 25), dejando abierta esa incompletitud que nace de la perplejidad:

Esa muchacha no se conoce sino a través de ir viviendo sin rumbo. Si cometiese la tontería de preguntarse «¿quién soy yo?» caería extendida y de lleno en el suelo. Es que «¿quién soy yo?» provoca necesidad. ¿Y cómo satisfacer la necesidad? Quien se indaga está incompleto.

\section{A modo de cierre}

El derecho cobra sentido en tanto y cuanto es un regulador de conductas sociales, y no es cualquier regulador, sino uno que tiene un ideal de realización de valores como la igualdad, la paz, la libertad y la buena vida. En el proceso de creación y aplicación (también creativa) del derecho, siempre debemos preguntarnos sobre qué base fáctica estamos realizando esas tareas. En el peor escenario, los prejuicios y los estereotipos toman el lugar de la descripción y la explicación y, sobre esa base, el derecho refuerza y legitima desigualdades. Contra ese escenario, hay que dar una lucha cada vez más difícil, pero igual de necesaria. Decía Levrero (2018: 13): «ciertas experiencias extraordinarias no pueden ser narradas sin que se desnaturalicen; es imposible llevarlas al papel». Y es justamente cuando nos encontramos con lo más ordinario, que parece que se explica solo, o lo extraordinario, que parece resistir cualquier intento de pasarlo al papel o al habla, cuando las ciencias sociales tienen su mayor desafío. 
Desnaturalizar nuestro sentido común y ser capaces de describir lo aparentemente indescriptible. Entre esos extremos, igual de inhóspitos, quienes enseñamos derecho tenemos una gran tarea que realizar, similar a la que nos ocupa cuando investigamos. Preguntar lo que ya nadie pregunta, ya sea porque se da por sentada una respuesta (aunque, a todas luces, esa respuesta deje a parte de la humanidad despojada de derechos fundamentales) o porque nadie se ha hecho la pregunta o, peor aún, porque se sanciona con el ridículo a quien trata de hacerla, es parte de lo que nos ocupa como docentes de derecho.

Este artículo tuvo como objetivo presentar e interrogar algunas herramientas que considero aptas para ver el revés de la trama, para tomar en cuenta lo que, en muchas ocasiones, desdeñamos porque es tan evidente que ha sido invisibilizado o porque no nos han enseñado a mirarlo. Seguramente, hay muchas otras herramientas y espero que podamos construir un diálogo acerca de cuáles utilizamos, cómo las hemos adaptado, qué ventajas y desventajas presentan y en qué medida podemos trasponerlas a nuestras prácticas.

\section{Referencias}

Bachelard, Gaston (1999). La formación del espíritu científico. Contribución a un psicoanálisis del conocimiento objetivo. Buenos Aires: Siglo XXI.

CLÉRICO, Laura (2017). «Derecho constitucional y derechos humanos: haciendo manejable el análisis de estereotipos». Revista Derechos en Acción, 2 (5). Disponible en bit.ly/2Kh2omY.

Chejfec, Sergio (2000). Boca de lobo. Buenos Aires: Anagrama.

CoHen, Stanley (2005). Estados de negación. Ensayo sobre atrocidades y sufrimiento. Buenos Aires: Eudeba.

De Sousa Santos, Boaventura (2000). «Hacia una concepción multicultural de los derechos humanos». DOXA, 10 (20). Disponible en bit.ly/2W5kvyH.

ELSTER, Jon (1996). Tuercas y tornillos. Una introducción a los conceptos básicos de las ciencias sociales. Barcelona: Gedisa.

GADAMER, Hans-Georg (1977). Verdad y método. Tomo I. Salamanca: Sígueme.

GeErTz, Clifford (1994). "Conocimiento local: Hecho y ley en la perspectiva comparativa». En Conocimiento local. Ensayos sobre la interpretación de las culturas (pp. 195-262). Barcelona: Paidós.

-. (1973). «Descripción densa: hacia una teoría interpretativa de la cultura». En La interpretación de las culturas (pp. 3-30). Barcelona: Gedisa.

Habermas, Jürgen (1994). «Conocimiento e interés». En Ciencia y técnica como «ideología» (pp. 33-48). Madrid: Tecnos.

HANDKe, Peter (1994). El miedo del portero al penalty. Madrid: Alfaguara.

JablonkA, Iván (2017). Laëtitia o el fin de los hombres. Buenos Aires: Anagrama. 
Levrero, Mario (2018). La novela luminosa. Buenos Aires: Random House.

Lipovetsky, Gilles y Jean Serroy (2015). La estetización del mundo. Vivir en la época del capitalismo artístico. Barcelona: Anagrama.

LisPeCtOR, Clarice (2015). La hora de la estrella. Buenos Aires: Corregidor.

Mcewan, Ian (2016). La ley del menor. Barcelona: Anagrama.

Moore, Lorrie (2019). ¿Quién se hará cargo del hospital de ranas?. Buenos Aires: Eterna Cadencia.

Morrison, Toni (1993). Beloved. Barcelona: Ediciones B.

SARTRE, Jean-Paul (1985). Réflexions sur la question juive. París: Gallimard.

Schweblin, Samanta (2017). «Mi hermano Walter». En Pájaros en la boca (pp. 106108). Buenos Aires: Penguin Random House.

Segato, Rita, (2013). La escritura en el cuerpo de las mujeres asesinadas en Ciudad Juárez. Buenos Aires: Tinta Limón.

VAN Hoecke, Mark (2014). «Doctrina jurídica: ¿Qué método(s) para qué tipo de disciplina?». Ciencia Jurídica, 3 (6): 127-148. Disponible en bit.ly/379LZtl.

\section{Sobre la autora}

NanCy CARDinaux es abogada, especialista en Ciencias Sociales y en Sociología Jurídica, y doctora en Derecho y Ciencias Sociales. Además, es profesora titular ordinaria de la Universidad Nacional de La Plata, profesora titular regular de la Universidad de Buenos Aires e investigadora independiente del Consejo Nacional de Investigaciones Científicas y Técnicas de la República Argentina. Su correo electrónico es nancycardinaux@gmail.com. (D) https://orcid.org/oooo-0003-0605-343X. 